\title{
The Australasian COVID-19 Trial (ASCOT) to assess clinical outcomes in hospitalised pa- tients with SARS-CoV-2 infection (COVID-19) treated with lopinavir/ritonavir and/or hydroxychloroquine compared to standard of care: A structured summary of a study protocol for a randomised controlled trial
}

Justin T. Denholm ${ }^{1 *}$ (D) Joshua Davis ${ }^{2,3}$, David Paterson ${ }^{4,5}$, Jason Roberts ${ }^{4,6,7}$, Susan Morpeth ${ }^{8}$, Thomas Snelling ${ }^{9}$, Dominica Zentner ${ }^{10}$, Megan Rees ${ }^{11}$, Matthew O'Sullivan ${ }^{12,13}$, David Price ${ }^{14,15}$, Asha Bowen ${ }^{16}$, Steven Y. C. Tong ${ }^{1,2}$ and for the ASCOT Investigator Group

\begin{abstract}
Objectives: To determine if lopinavir/ritonavir +/- hydroxychloroquine will reduce the proportion of participants who survive without requiring ventilatory support, 15 days after enrolment, in adult participants with non-critically ill SARS-CoV-2 infection.

Trial design: ASCOT is an investigator-initiated, multi-centre, open-label, randomised controlled trial. Participants will have been hospitalised with confirmed COVID-19, and will be randomised 1:1:1:1 to receive lopinavir /ritonavir, hydroxychloroquine, both or neither drug in addition to standard of care management.

Participants: Participants will be recruited from $>80$ hospitals across Australia and New Zealand, representing metropolitan and regional centres in both public and private sectors. Admitted patients will be eligible if aged $\geq 18$ years, have confirmed SARS-CoV-2 by nucleic acid testing in the past 12 days and are expected to remain an inpatient for at least 48 hours from the time of randomisation. Potentially eligible participants will be excluded if admitted to intensive care or requiring high level respiratory support, are currently receiving study drugs or their use is contraindicated due to allergy, drug interaction or comorbidities (including baseline QTc prolongation of 470ms for women or $480 \mathrm{~ms}$ for men), or death is anticipated imminently.

(Continued on next page)
\end{abstract}

\footnotetext{
* Correspondence: justin.denholm@mh.org.au

'Victorian Infectious Diseases Service, The Royal Melbourne Hospital, and Doherty Department University of Melbourne, at the Peter Doherty Institute for Infection and Immunity, 792 Elizabeth Street, Melbourne, Victoria, Australia

Full list of author information is available at the end of the article
}

C C The Author(s). 2020 Open Access This article is licensed under a Creative Commons Attribution 4.0 International License, which permits use, sharing, adaptation, distribution and reproduction in any medium or format, as long as you give appropriate credit to the original author(s) and the source, provide a link to the Creative Commons licence, and indicate if changes were made. The images or other third party material in this article are included in the article's Creative Commons licence, unless indicated otherwise in a credit line to the material. If material is not included in the article's Creative Commons licence and your intended use is not permitted by statutory regulation or exceeds the permitted use, you will need to obtain permission directly from the copyright holder. To view a copy of this licence, visit http://creativecommons.org/licenses/by/4.0/ The Creative Commons Public Domain Dedication waiver (http://creativecommons.org/publicdomain/zero/1.0/) applies to the data made available in this article, unless otherwise stated in a credit line to the data. 
(Continued from previous page)

Intervention and comparator: Participants will be randomised 1:1:1:1 to:

Group 1: standard of care;

Group 2: lopinavir (400mg) / ritonavir (100mg) twice daily for 10 days in tablet form;

Group 3: hydroxychloroquine (800mg) 4x200mg administered 12 hours apart on Day 1, followed by 400mg twice a day for 6 days;

Group 4: lopinavir /ritonavir plus hydroxychloroquine.

Main outcomes: Proportion of participants alive and not having required intensive respiratory support (invasive or non-invasive ventilation) at 15 days after enrolment. A range of clinical and virological secondary outcomes will also be evaluated.

Randomisation: The randomisation schedule will be generated by an independent statistician. Randomisation will be stratified by site and will be in permuted blocks of variable block size. The randomised sequence allocation will only be accessible to the data management group, and site investigators will have individual participant allocation provided through a web-based trial enrolment platform.

Blinding (masking): This is an open-label study, with researchers assessing the laboratory outcomes blinded to treatment allocation. No unblinding procedures relating to potential adverse effects are therefore required.

Numbers to be randomised (sample size): We assumed that 5\% of participants receiving standard of care would meet the primary outcome, aimed to evaluate whether interventions could lead to a relative risk of 0.5 , assuming no interaction between intervention arms. This corresponds to a required sample size of 610 per arm, with a 5\% two-sided significance level (alpha) and 80\% power. The total sample size therefore is planned to be 2440.

Trial Status: ASCOT protocol version 3, May 5, 2020. Recruitment opened April 4, 2020 and is ongoing, with planned completion of enrolment July 31, 2021.

Trial registration: Australian New Zealand Clinical Trials Registry (ACTRN12620000445976). Prospectively registered April 6, 2020.

Full protocol: The full protocol is attached as an additional file, accessible from the Trials website (Additional file 1). In the interest in expediting dissemination of this material, the familiar formatting has been eliminated; this Letter serves as a summary of the key elements of the full protocol.

Keywords: COVID-19, Randomised controlled trial, protocol, hydroxychloroquine, lopinavir, ritonavir

\section{Supplementary information}

Supplementary information accompanies this paper at https://doi.org/10. 1186/s13063-020-04576-9.

\section{Additional file 1}

\section{Acknowledgements}

\section{The ASCOT Investigator Group}

Study Principal Investigators Joshua Davis, Justin Denholm, Steven Tong. Trial Steering Committee Asha Bowen (Chair), Megan Rees, David Paterson, David Price, Susan Morpeth, Matthew O'Sullivan, Jason Roberts, Thomas Snelling, Sue Anderson, Zoe McQuilton, Bala Venkatesh, Naomi Hammond, Vivekanend Jha. Site principal investigators. Victoria John Burston, James McMahon, Patrick Charles, Robert Commons, Daniel O'Brien, Andrew Mahoney, David Sheffield, Lyn-Li Lim, Brad Gardiner, Thomas Schulz, Joseph Torresi, Roy Chean, Joseph Sasadeusz, Ben Rogers, Craig Aboltins, Kasha Singh, Michelle Yong, David Lister, Kumar Visvanathan, James Molton, Alex Tai. New South Wales Rachel Chalmers, Marianne Martinello, Paul Wilson, Timothy Gray, Sarah Coghill, Hong Foo, Archana Sud, Jacob Williams, Nilar Lwin, Jeffrey Post, Sebastian van Haal, Richard Sullivan, Gail Matthews, Benjamin Chi Hin Kwan, Andrew Slack, Omar Shum, Belinda Cochrane, Ravindra Dotel, Timothy Gray, Timothy Gilbey, Michael Mina, Yuen Su, Chris Trethewy, Bernie Hudson, Arunavo Chatterji, Christaan Mostert. West Australia David New, Edward Raby, Sionh Hui, Owen Robinson, Julie Hart, Shu Jin Tan, Astrid AreIlano, Jonathan Chambers. Northern Territory Jane Davis. Queensland Nastaran Rafiei, Simon Smith, Marjoree Sehu, Janath da Silva, Paul Griffin, Andrew Henderson, Khin Chaw, Keat Choong, Andrew Burke, Christopher Heather.
Australian Capital Territory Sanjaya Senanayake. South Australia Mark Boyd, Emily Rowe, Mick Anagnostou. Tasmania Ali Trad, Alison Ratcliff. New Zealand Susan Morpeth, Jack Dummer, Hassan Bhally, Massimo Giola, Kate Grimwade, Catharina Li-Lin Chang, Ayesha Verrall, Stephen Hogg, Dalilah Restropo, Michael Maze, Stephen Ritchie. ASCOT Biobank Steering Committee Craig Gedye, Judy Chang, Michael Maze, Priyanka Pillai, Katie Flanagan. Operational group Jocelyn Mora, Jenny Post, Eileen Lam, Roberta Littleford, Naomi Knoblauch, Sandy Slow.

\section{Authors' contributions}

The ASCOT protocol was conceived and drafted by SYCT, JTD, JDa, and all authors were involved in review, amendments and approval of the final protocol. DP and TS had primary responsibility for statistical methodology. JR and DZ provided particular input in pharmacological dosing and safety considerations.

\section{Funding}

ASCOT has been initially funded in Australia by a variety of philanthropic donors, and in New Zealand by the Health Research Council, who have no role in study design, analysis and decision to publish.

\section{Availability of data and materials}

Data recorded for this trial will be stored securely in a dedicated research database, accessible only to authorised investigators and study monitors. Findings will be submitted for presentation at appropriate conferences and for publication in peer-reviewed literature. Study updates will also be made available through the ASCOT website (https://www.ascot-trial.edu.au/). 
Investigators will actively pursue opportunities for data sharing, including individual participant meta-analysis.

\section{Ethics approval and consent to participate}

This trial has been approved by the Melbourne Health Human Research Ethics Committee (HREC/62646/MH-2020), with initial approval given April 3, 2020. Additional ethics approvals have been given by Northern B Health and Disability Ethics Committee in New Zealand (20/NTB/75), Human Research Ethics Committee of the Northern Territory Department of Health and Menzies School of Health Research (HREC-2020-3713), Tasmania Health and Medical Human Research Ethics Committee (ref 21640), and the St John of God Health Care Human Research Ethics Committee (ref 1662). We certify that all appropriate ethical approval processes have been conducted as described above.

Informed consent to participate will be obtained prior to enrolment. Due to the stringent measures in infection control in hospitals, verbal consent will be obtained instead of written consent, with additional measures provided for stringent documentation and independent confirmation of consent to participate.

\section{Consent for publication}

Not applicable

\section{Competing interests}

The authors declare that they have no competing interests.

\section{Author details}

'Victorian Infectious Diseases Service, The Royal Melbourne Hospital, and Doherty Department University of Melbourne, at the Peter Doherty Institute for Infection and Immunity, 792 Elizabeth Street, Melbourne, Victoria, Australia. ${ }^{2}$ Menzies School of Health Research, Charles Darwin University, Darwin, Australia. ${ }^{3}$ Department of Infectious Diseases, John Hunter Hospital, Newcastle, NSW, Australia. ${ }^{4}$ University of Queensland Centre for Clinical Research, Faculty of Medicine \& Centre for Translational Anti-infective Pharmacodynamics, School of Pharmacy, The University of Queensland, Brisbane, Australia. ${ }^{5}$ Department of Infectious Diseases, Royal Brisbane and Women's Hospital, Brisbane, Queensland, Australia. ${ }^{6}$ Departments of Pharmacy and Intensive Care Medicine, Royal Brisbane and Women's Hospital, Brisbane, Australia. ${ }^{7}$ Division of Anaesthesiology Critical Care Emergency and Pain Medicine, Nîmes University Hospital, University of Montpellier, Nîmes, France. ${ }^{8}$ Middlemore Hospital, Counties Manukau District Health Board, Auckland, New Zealand. ${ }^{9}$ School of Public Health, University of Sydney, Sydney, New South Wales, Australia. ${ }^{10}$ Department of Cardiology, The Royal Melbourne Hospital and Department of Medicine, University of Melbourne, Melbourne, Victoria, Australia. ${ }^{11}$ Department of Respiratory Medicine, The Royal Melbourne Hospital and Department of Medicine, University of Melbourne, Melbourne, Victoria, Australia. ${ }^{12}$ Centre for Infectious Diseases and Microbiology, Westmead Hospital, Westmead, New South Wales, Australia. ${ }^{13}$ University of Sydney, Sydney, New South Wales, Australia. ${ }^{14}$ Centre for Epidemiology \& Biostatistics, Melbourne School of Population \& Global Health, The University of Melbourne, Melbourne, Victoria, Australia.

${ }^{15}$ Victorian Infectious Diseases Reference Laboratory Epidemiology Unit at the Peter Doherty Institute for Infection \& Immunity, Royal Melbourne Hospital and The University of Melbourne, Melbourne, Victoria, Australia.

${ }^{16}$ Telehealth Kids Institute, Perth, West Australia, Australia.

Received: 28 June 2020 Accepted: 2 July 2020

Published online: 14 July 2020

\section{Publisher's Note}

Springer Nature remains neutral with regard to jurisdictional claims in published maps and institutional affiliations.

\section{Ready to submit your research? Choose BMC and benefit from:}

- fast, convenient online submission

- thorough peer review by experienced researchers in your field

- rapid publication on acceptance

- support for research data, including large and complex data types

- gold Open Access which fosters wider collaboration and increased citations

- maximum visibility for your research: over $100 \mathrm{M}$ website views per year

At BMC, research is always in progress.

Learn more biomedcentral.com/submissions 